\title{
To defer or not defer? UK state pension and work decisions in a lifecycle model.
}

\author{
Ricky Kanabar*\& Peter Simmons ${ }^{\dagger}$
}

May 23, 2016

\begin{abstract}
The UK state pension (which depends only on age) includes an option to defer take up which yields either a subsequent lump sum or higher weekly pension. We analyse the joint decisions on pension deferral and intertemporal labour supply/participation in a lifecycle setting. We show that deferral is purely a financial decision, but the impact of deferral on work decisions depends on preferences, wage rates, non-labour income and initial wealth. To exactly characterise this we use a quasilinear utility function, and provide calibrated simulations. We also discuss the choice between a lump sum or increased weekly pension.

JEL classification: J14, J18, J22 \& J26.

Key words: Retirement, Labour Supply, Ageing, UK State Pension.
\end{abstract}

\section{Introduction}

Aging populations and longevity raise issues regarding labour force participation rates, savings and pensions especially amongst the elderly. These are also important issues for government fiscal balance since tax receipts, state pensions and work conditional benefits obviously vary with labour and capital incomes.

The aim of the state pension system in the UK is to alleviate poverty in old age, Beveridge (1942), and in this sense it is a long term government commitment. Governments respond by encouraging later retirement and/or raising the age of eligibility for receipt of a state pension. All eligible state pensioners are able to defer their pension for a period of time (in exchange for an increased weekly pension when they do subsequently decide to claim), deferral does not have to be linked with their labour market status although often is (Coleman et al., 2008).

The possibility of State Pension deferral has implications for the planned savings and work pattern of individuals through changing their lifetime pattern

*Institute for Social and Economic Research, University of Essex, Colchester, Essex, CO4 3SQ. Email: rkanabar@essex.ac.uk

${ }^{\dagger}$ Department for Economics, University of York, York, YO10 5DD. Email: peter.simmons@york.ac.uk 
of non-labour income. What implications will deferral have for their work and savings patterns? Can deferral induce individuals to stay on longer in paid work? In this paper we formally analyse the joint deferral and intertemporal labour participation decisions in a lifecycle setting.

The economic implications of ageing and increasing longevity has led to a flurry of research concerned with labour supply at or around retirement age (see inter alia Meghir and Whitehouse,1997; Banks and Smith, 2006; Bloom, Canning and Morre, 2014). Disney and Smith (2002) formally analyse the effect of the abolition of the Earnings Rule (which effectively placed a very high marginal tax rate on individuals who wanted to claim their pension and continue working), and as a side issue also consider pension deferral. Their findings suggest that after abolition, male weekly hours (above State Pension Age (SPA)) rose by approximately 4 hours, whilst for women it rose by 2 hours; however Disney and Smith (2002) do not explicitly consider the effects of pension deferral on labour supply. Farrar et al (2012) compare the two deferral options available under current State Pension legislation and conclude under most simulations that the incremental option (additional weekly state pension) generally tended to more lucrative.

With perfect capital markets we find the deferral decision is independent of preferences, wage rates or initial wealth. It is a purely financial decision: choose to defer if it raises the present value of non-labour income. However the effect of deferral on intertemporal labour supply does depend on preferences, wage rates and initial wealth. In a general model we sketch the qualitative effects but to get analytical and empirically applicable results, we then specify preferences. After deriving analytical expressions for the effects on reservation wages for different intertemporal labour participation patterns, we calibrate these to compute the size of the impacts. The present deferral scheme gives about a $2 \%$ increase in the reservation wage for full time work for 12 months of deferral. If an individual does defer, under the present system he can take the later rewards as either a lump sum or as an increase in the weekly payment. We analyse the choice between these, examining the effects of life expectancy/length of deferral and of interest rates.

In section 2 we lay out a general framework which encompasses the effects of pension deferral on optimal labour supply through the role of the present value of non-labour income. In section 3 we show the effects of regime switches on the optimal labour supply, using a form of preferences used widely in the literature. Section 4 compares the two deferral options available under current UK State Pension legislation. Section 5 concludes.

\section{The model}

With perfect capital markets and in a world of certainty, financial wealth can be transferred intertemporally by the consumer. So one would expect that the benefits of deferring a state pension will depend only on a comparison between the implicit interest rate used in the government set terms of deferral and the 
market interest rate. This is because individuals will only defer if it raises their disposable wealth at the date of deferral, through raising the present value of current and future non-labour income in the form of pension receipts. For individuals who defer we would expect optimal adjustment in consumption $c$, and leisure $L$ as they intertemporally smooth the marginal utility of consumption. There will be wealth effects on present and future labour participation and consumption. Disney \& Smith (2002) point out that there may be labour participation effects of changes in the pension rules, or more specifically in the implicit wage income an individual can earn in the absence of an earnings rule. Without perfect and complete capital markets it is more complex. For example with uncertainty about other future income sources and especially about the remaining length of life, the decision to defer or not is much less clear.

Similarly individuals who face borrowing constraints are less likely to defer when they have the opportunity. However a recent paper by Crawford and O'Dea (2014) suggests credit constraints are unlikely to be in operation for many older English households. Their paper using survey data from the English Longitudinal Study of Ageing (ELSA) linked to administrative data shows that on reaching retirement $92 \%$ of their sample of older English households had a level of total wealth in excess of what is optimal. ${ }^{1}$ Even if one were to exclude housing wealth from observed wealth holdings, three quarters of the sample had levels of wealth in excess of what is optimal. Indeed, many studies have demonstrated the significant wealth holdings of older households in developed economies and suggest credit constraints are unlikely to be binding for such households (see inter alia: Curme and Even, 1995; Wolff, 1998; Scholz et al. 2004; Crook, 2006; Le Blanc et al. 2014).

To see how a decision to defer impacts on current and future labour supply as individual leisure preferences and wage rates vary needs a formal framework. We present this next. Our interest is on individuals at the end of their life, so we take a two period model $t=T-1, T$. There is a single financial asset $\mathrm{A}$ in which borrowing or saving is allowed and whose one period real interest factor is $r$. The individual starts with a stock $A_{T-1}$ of the financial asset at the beginning of period T-1. Each period the individual receives non-labour income $y_{T-1}, y_{T}$ part of which is pension receipts in the period. The pension receipts in each period depend on the deferral decision. Individuals also have a fixed time endowment each period of one unit of time which can be used either for leisure or work. To focus on labour participation we assume that the only work options available are either $L=0$ (full time work) or $L=1$ (zero work). ${ }^{2}$ With these assumptions wealth at the start of $T-1, x_{T-1}$, is

\footnotetext{
${ }^{1}$ Where optimal is defined as maintaining a household's preretirement standard of living through retirement.

${ }^{2}$ The fact we have considered corner solutions means there is the possibility for individuals to move from retirement back into paid work, so called unretirement (Maestas, 2010). We assume this is cost free however it could be argued this assumption is untenable. Individuals may have to retrain and having been out of the labour this is more costly due to depreciation in the individual's stock of human capital. Introducing a switching cost would imply an individual's reservation wage increases ceterus paribus in order to account for the higher reentry cost. However it would not fundamentally change the main result of the paper.
} 


$$
\begin{gathered}
x_{T-1}=A_{T-1}+y_{T-1}+\frac{y_{T}}{r}+w_{T-1}\left(1-L_{T-1}\right)+\frac{w_{T}\left(1-L_{T}\right)}{r} \\
=Y_{T-1}+w_{T-1}\left(1-L_{T-1}\right)+\frac{w_{T}\left(1-L_{T}\right)}{r}
\end{gathered}
$$

Where $Y_{T-1} \equiv A_{T-1}+y_{T-1}+\frac{y_{T}}{r}$. Individuals maximise a time additive concave utility function which depends on a single consumption good, $c$, and leisure $L$ subject to their remaining lifetime budget constraint:

$$
\begin{gathered}
\max _{c_{T-1}, c_{T}, L_{T-1}, L_{T}} u\left(c_{T-1}, L_{T-1}\right)+\delta u\left(c_{T}, L_{T}\right) \\
\text { st } c_{T-1}+\frac{c_{T}}{r}=x_{T-1} \\
0 \leq L_{t} \leq 1
\end{gathered}
$$

where $\delta$ is the rate of time preference.

To highlight how deferral affects lifetime utility, we solve the full lifecycle problem in two steps: first for a given deferral choice and given lifetime leisure choices, we solve out the optimal lifetime consumption pattern. This gives us a semi-indirect utility function in which maximal lifetime utility after adjusting the consumption pattern depends only on the leisure choices and on initial wealth $x_{T-1}$ at time T-1.

Following this process, we substitute out the lifetime budget constraint reducing the optimal consumption problem (for an interior solution) at fixed values of leisure and $x_{T-1}$ to

$$
\max _{c_{T-1}} u\left(c_{T-1}, L_{T-1}\right)+\delta u\left(r\left(x_{T-1}-c_{T-1}\right), L_{T}\right)
$$

If we assume that consumption each period is interior, the first order condition, equation (3) below, shows that the marginal utility of consumption at each time period must be intertemporally balanced: ${ }^{3}$

$$
\frac{\partial u_{T-1}}{\partial c_{T-1}}=r \delta \frac{\partial u_{T}}{\partial c_{T}}
$$

(and given concavity in $c$ this condition is also sufficient).

Lifetime wealth $x_{T-1}$ depends on the deferral decision $\mathrm{s}=\mathrm{d}$,nd since this partly determines income in each period via the pension. For fixed values of $L_{T-1}, L_{T}$ and $x_{T-1}^{s}$ this gives a semi-indirect utility, $\mathrm{v}($.$) , defined as:$

$$
v\left(L_{T-1}, L_{T}, x_{T-1}\right)=\max _{c_{T-1}}\left[u\left(c_{T-1}, L_{T-1}\right)+\delta u\left(r\left(x_{T-1}^{s}-c_{T-1}\right), L_{T}\right)\right]
$$

which is increasing in all its arguments and also concave in the leisures of each period (see for example Stokey, Lucas, Prescott, 1989). The remaining problems

\footnotetext{
${ }^{3}$ Assuming that the marginal utility of consumption in any period becomes arbitrarily high as consumption in that period becomes very small ensures an interior solution.
} 
for the individual are to choose optimal labour supply in each period and, via deferral $\left(Y^{s}\right), x_{T-1}^{s}$ :

$$
\max _{L_{T}, L_{T-1}, x_{T-1}} v\left(L_{T-1}, L_{T}, x_{T-1}\right) \text { st } 0 \leq L_{i} \leq 1
$$

Our main focus is on the interaction between labour participation decisions, saving and pension deferral so we focus on just full time and zero work options for each time period. ${ }^{4}$ In the second step we jointly determine the best deferral and leisure choice decisions, these decisions are discrete which implies comparing semi-indirect utility function values for different combinations of discrete choices.

Should an individual defer their pension from $T-1$ to $T$ ? For any concave increasing function $v$ and for any values of $L_{T-1}, L_{T}, v$ is maximised wrt $x_{T-1}$ by choosing the highest value of $x_{T-1}$. This is the best choice for any preferences and any labour participation decisions that the indvidual chooses. Since capital markets are perfect he can rearrange $x_{T-1}$ through time in any way he wishes. So if wage rates and preferences make it best to work only today he can save, or if only tomorrow can borrow as he wishes. Recalling that $x_{T-1}=1$, the individual will choose the deferral option which has the higher present value of pension payments which are embedded in Y. The state pension now available at $T-1$ is $p$ per period. Thus if the individual has non-state pension, non-labour income (such as occupational pension income and investment income) of $y_{T-1}^{o} ; y_{T}^{o}$ then without deferral they receive $y_{T-1}=y_{T-1}^{o}+p ; y_{T}=y_{T}^{o}+p$. With deferral they receive $y_{T-1}=y_{T-1}^{o} ; y_{T}=y_{T}^{o}+r_{g} p$ where $r_{g}$ is the implicit interest rate factor set by the government in the terms of deferral. Deferral will be chosen iff it raises lifetime non-labour income $Y=y_{T-1}+\left(y_{T} / r\right)$. Without deferral $Y^{n d}=$ $y_{T-1}^{0}+p+\left[\left(y_{T}^{0}+p\right) / r\right]$ while with deferral $Y^{d}=y_{T-1}^{0}+\left[\left(y_{T}^{0}+r_{g} p+p\right) / r\right]$. Equating these two expressions implies that the individual is better off deferring iff $r_{g}>r$. The implicit interest rate factor $r_{g}$ is common to all individuals so variation amongst individuals in the decision to defer must be due to variation in the market interest rate available to individuals, and more generally to variation in borrowing constraints or other capital market imperfections, or to omitted issues like uncertainty over the length of life or spousal labour force status.

Once derral has been decided, the remaining choices are labour participation. There are four possible configurations of labour participation over the final two periods of life: full time work in both periods, zero work in both periods or full time work in one period and zero work in the other.

Define the lifecycle full incomes at the start of $T-1$ corresponding to each lifetime pattern of labour participation (the subscripts refer to the amount of

\footnotetext{
${ }^{4}$ If we included interior solutions for labour participation there would be 9 configurations. The way of getting the "reservation wages" above would be similar eg suppose $0<L_{T-1}<1$ and $L_{T}=0$. Let $L_{T-1}^{*}$ solve

$$
\frac{d v\left(L_{T-1}^{*}, 0, x\right)}{d L_{T-1}}=0 \text { and then require } \frac{d v\left(L_{T-1}^{*}, 0, x\right)}{d L_{T}}<0
$$
}

See Appendix B for full details. 
leisure in each period so e.g. 01 corresponds to full time work at $T-1$ but zero work at $T$ ) for a given pension deferral decision $s=d, n d$ yielding $Y^{s}$

$$
\begin{aligned}
& X_{11}^{s}=A_{T-1}+Y^{s} \equiv Z^{s} \\
& X_{00}^{s}=A_{T-1}+Y^{s}+r w_{T-1}+w_{T}=Z^{s}+r w_{T-1}+w_{T} \\
& X_{01}^{s}=A_{T-1}+Y^{s}+r w_{T-1}=Z^{s}+r w_{T-1} \\
& X_{10}^{s}=A_{T-1}+Y^{s}+w_{T}=Z^{s}+w_{T}
\end{aligned}
$$

We have a ranking of the full incomes $X_{00}^{s}>X_{01}^{s}>X_{11}^{s}, X_{00}^{s}>X_{10}^{s}>X_{11}^{s}$.

The possible payoffs corresponding to these labour participation patterns are then $v\left(1,1, X_{11}^{s}\right), v\left(0,1, X_{01}^{s}\right), v\left(1,0, X_{10}^{s}\right)$ and $v\left(0,0, X_{00}^{s}\right)$. Note that if $v\left(1,1, X_{11}^{s}\right)>$ $v\left(0,1, X_{01}^{s}\right), v\left(1,0, X_{10}^{s}\right)$ then $v\left(1,1, X_{11}^{s}\right)>v\left(0,0, X_{00}^{s}\right)$ from the monotonicity of $v()$ in all its arguments.

Given the deferral choice, the only differences in the full incomes between participation patterns are in the value of the time endowment which arises in periods of work and depends on the wages of those periods. A suitable idea of the time profile of reservation wages between any two alternative profiles of labour participation, for a given deferral decision, is a pair $w_{T-1}, w_{T}$ giving indifference between the two patterns of labour participation. So with $Z^{s}=A_{T-1}+Y^{s}$, and similarly for wages $w^{s}$ where $s=d, n d$ we can define:

$$
\begin{aligned}
V_{11}^{s} & =v\left(1,1, Z^{s}\right)=v\left(1,0, Z^{s}+w_{T}^{s, 11,10}\right)=V_{10}^{s} \\
V_{01}^{s} & =v\left(0,1, Z^{s}+w_{T-1}^{s, 01,10}\right)=v\left(1,0, Z^{s}+w_{T}^{s, 01,10}\right)=V_{10}^{s} \\
V_{11}^{s} & =v\left(1,1, Z^{s}\right)=v\left(0,0, Z^{s}+r w_{T-1}^{s, 00,10}+w_{T}^{s, 00,10}\right)=V_{00}^{s} \\
V_{11}^{s} & =v\left(1,1, Z^{s}\right)=v\left(1,0, Z^{s}+w_{T-1}^{s, 11,01}\right)=V_{01}^{s} \\
& \Rightarrow v\left(0,0, Z^{s}+r w_{T-1}+w_{10}^{s, 11}\right)<v\left(1,0, Z^{s}+w_{10}^{s, 11}\right)
\end{aligned}
$$

In general finite positive wages ensuring these indifferences exist if one assumes the Inada conditions hold for $\frac{\partial U}{\partial L}$, however for certain forms of the utility function (such as quasilinear) this is not true as we show in the next section. Nonetheless the general pattern of how lifecycle labour participation is determined is clear. For the pattern $i j$ to be optimal (i.e. participation state $i$ in period $T-1$ and $j$ in $T$ ) to be optimal we require that $V_{i j}^{s}>V_{k l}^{s}$ for each other possible participation profile $k l$. How the optimal participation profile varies with $Z$ and current wages depends on the form of the utility. There are some basic results just from monotonicity of $v()$ in its arguments. Thus if $V_{11}^{s}=V_{10}^{s}$ then $V_{00}^{s}<V_{10}^{s}$. In general for a given $Z$ and utility function, there will be a region of high wages in both periods where it is optimal to work full time in both periods (corresponding to $V_{00}^{s}>V_{10}^{s}, V_{01}^{s}, V_{11}^{s}$ ). Similarly there will be a region of low wages in both periods where it is not optimal to work in either period (corresponding to $V_{11}^{s}>V_{10}^{s}, V_{01}^{s}, V_{00}^{s}$ ). And finally there will be two regions: one with high wages in $T-1$ but low wages in $T$ (corresponding to $\left.V_{01}^{s}>V_{10}^{s}, V_{00}^{s}, V_{11}^{s}\right)$, where it is optimal to work full time in $T-1$ but not work at all at $T$, and conversely a region of high wages at $T$ but low wages at $T-1$ 
where it is optimal to stay out of the labour market at $T-1$ but work full time at $T$ (corresponding to $V_{10}^{s}>V_{00}^{s}, V_{01}^{s}, V_{11}^{s}$ ). With given preferences, $Z$ and wage rates of each period, the optimal profile of labour participation for a given deferral choice over the two periods is determined.

How does an improvement in the deferral option affect the optimal participation profile? Deferral is only taken up if it raises the present value of non-labour income including the pension stream. This change in wealth changes the demand for leisure in each period. If leisure is a normal good, an increase in wealth increases the demand for leisure in each period. So we would generally expect a drop in work hours in each period when an individual prefers to defer. If an individual was planning full time work in each period in the absence of deferral but chooses to defer, then if their wage rates were close to the reservation wage in one of the periods (as computed above), with deferral his optimal profile may switch into zero work in that period. Disney and Smith (2002) consider the effects of relaxation of the earnings rule on labour supply participation of older workers in the UK. Their empirical results indicate that increasing generosity of work incentives, such as reducing the marginal tax rate on earnings for older workers increases the number of hours worked. ${ }^{5}$ This suggests strong income effects are at work, whereas in our model deferral has a direct wealth effect and under standard assumptions would act to increase the amount of leisure consumed.

To see the impact of pension deferral on lifecycle labour force participation we need to know more about the wage regions corresponding to different labour participation patterns and how these vary with $Z$. To determine this we have to resort to a specification of preferences which allows us to explicitly compute the labour participation areas and the ways in which they vary with $Z$. From this we can predict which parts of the intertemporal wage rate distribution will lead to a switch to zero hours of work in either or both of periods $T-1, T$ on introduction of the pension deferral option. We can then also see how deferral will impact on consumption and savings in different parts of the wage rate distribution.

\section{Quasilinear utility.}

In this section we take a commonly used specification for the utility function (Gustman and Steinmeier (2010), Blau (2012)), in which consumption, c, is isoelastic and labour, $L$, is quasilinear. First we derive optimal saving and labour supply regimes. We find the channels through which pension deferral affects optimal labour supply. In this specification, remaining lifetime preferences are given by

$$
u\left(c_{T-1}, L_{T-1}\right)+\delta u\left(c_{T}, L_{T}\right)=\frac{C_{T-1}^{\alpha}}{\alpha}+h_{T-1} L_{T-1}+\delta\left(\frac{C_{T}^{\alpha}}{\alpha}+h_{T} L_{T}\right)
$$

\footnotetext{
${ }^{5}$ This may not hold true for all workers depending on whether their income is above or below the earnings rule threshold.
} 
In Appendix A we derive the savings function $A_{T}$ as

$$
A_{T}=\frac{x_{T-1}-(\delta r)^{1 /(\alpha-1)}\left(y_{T}+w_{T}\left(1-L_{T}\right)\right.}{1+r(\delta r)^{1 /(\alpha-1)}}
$$

where now $x_{T-1} \equiv A_{T-1}+y_{T-1}+w_{T-1}\left(1-L_{T-1}\right)$.

The resulting value function is:

$v\left(K^{s}, w_{T-1} L_{T-1}, L_{T}, w_{T}\right)=\frac{\left.\left(K^{s}+w_{T-1}\left(1-L_{T-1}\right)\right)+\frac{w_{T}\left(1-L_{T}\right)}{r}\right)^{\alpha}}{\alpha} D+h_{T-1} L_{T-1}+\delta h_{T} L_{T}$

where for a given deferral decision $s=n d, d, K^{s}$ is the sum of the cumulated value of initial wealth and lifetime non-labour income valued at $T$ :

$$
\begin{aligned}
K^{s} & \equiv r\left(A_{T-1}+y_{T-1}\right)+y_{T} \\
D & \equiv\left((\delta r)^{\alpha /(\alpha-1)}+\delta\right)
\end{aligned}
$$

$K^{s}$ varies with the deferral decision through varying lifetime non-labour income but is otherwise exogenous.

The semi-indirect utility function $v$, is isoelastic in disposable wealth at $T-1$ and linear in present and future leisures. Quasilinearity in leisure given the wealth effect of pension deferral, means that the income effects fall solely on participation. In Appendix B we derive the full set of leisure demands for these preferences with continuously varioable hours of work. However as stated above our main interest is on the links between pension deferral and labour force participation since in the context of extending working lives this is where the main policy interest lies. Since we restrict attention to leisure choices which are discrete $(0,1)$, then the best leisure/pension deferral combinations are given by the maximal semindirect utility level over the discrete combinations of leisure and deferral.

Conditional on deferral and hence $K^{s}$ the maximal utilities obtained from the lifecycle labour force regime (defined by the subscript notation) are defined as:

$$
\begin{gathered}
V_{00}^{s}\left(K, w_{T-1}, w_{T}\right)=\frac{\left(K^{s}+r w_{T-1}+w_{T}\right)^{\alpha}}{\alpha} D \\
V_{01}^{s}\left(K, w_{T-1}\right)=\frac{\left(K^{s}+r w_{T-1}\right)^{\alpha}}{\alpha} D+\delta h_{T} \\
V_{10}^{s}\left(K, w_{T}\right)=\frac{\left(K^{s}+w_{T}\right)^{\alpha}}{\alpha} D+h_{T-1} \\
V_{11}^{s}(K)=\frac{\left(K^{s}\right)^{\alpha}}{\alpha} D+h_{T-1}+\delta h_{T}
\end{gathered}
$$

This allows us to define six combinations of wages $w_{T-1}^{s, i}, w_{T}^{s, i} s=n d, d$ and 
$i=1 . .6$ which give indifference between pairs of maximal utility levels

$$
\begin{aligned}
(1) V_{00}^{s}\left(K^{s}, w_{T-1}^{s, 1}, w_{T}^{s, 1}\right) & =V_{01}^{s}\left(K^{s}, w_{T-1}^{s, 1}\right) \\
(2) V_{00}^{s}\left(K^{s}, w_{T-1}^{s, 2}, w_{T}^{s, 2}\right) & =V_{10}^{s}\left(K^{s}, w_{T}^{s, 2}\right) \\
(3) V_{00}^{s}\left(K^{s}, w_{T-1}^{s, 3}, w_{T}^{s, 3}\right) & =V_{11}^{s}\left(K^{s}\right) \\
(4) \quad V_{01}^{s}\left(K^{s}, w_{T-1}^{s, 4}\right) & =V_{10}^{s}\left(K^{s}, w_{T}^{s, 4}\right) \\
(5) \quad V_{01}^{s}\left(K^{s}, w_{T-1}^{s, 5}\right) & =V_{11}^{s}\left(K^{s}\right) \\
(6) \quad V_{10}^{s}\left(K^{s}, w_{T}^{s, 6}\right) & =V_{11}^{s}\left(K^{s}\right)
\end{aligned}
$$

Using the detailed expressions for the various value functions Appendix $\mathrm{C}$ derives the critical wage combinations and shows that generally they are related as in Figure 1 below. ${ }^{6}$. Each of the lines labeled in Figure 1 correspond to the reservation wages $w_{T-1}^{s, i}, w_{T}^{s, i}$ giving indifference between pairs of maximal utility levels.

Using monotonicity of the value function expressions in terms of the wage rates, we can deduce regions of the wage space in which different intertemporal labour participation patterns are optimal as shown in Figure 2 below. The boundaries between the regions in Figure 2 correspond to the relevant parts of the lines in Figure 1: 1,2 giving lower bounds on full time work, 5, 6 giving upper bounds on the zero work region and 4 giving the division between working either just in $T-1$ or in $T$. Both Figures 1 and 2 are conditional on $K^{s}$ and therefore depend on the deferral choice.

\subsection{The effect of pension deferral on labour force partici- pation.}

To examine the impact of pension deferral which raises the present value of nonlabour income on lifecycle labour participation, we show how Figure 2 changes with $K^{s}$. Figures 3 and 4 shows that the effect on the optimal labour participation profile of an increase in $K$ depends on whether the utility value of leisure is higher in $T-1$ or $T$. In both cases the wage region with zero work in both periods expands and that with full time work in both periods contracts. But if the value of leisure is higher in period $T$ than $T-1$, the wage region with full time work only at $T-1$ expands at the expense of the wage region with

\footnotetext{
${ }^{6}$ In some cases there may be no positive wage pairs $w_{T-1}, w_{T}$ yielding indifference. In case (4) equating the expressions for $v_{01}=v_{10}$ yields the following equation:

$$
\left(K+r w_{T-1}\right)^{\alpha}=\left(K+w_{T}\right)^{\alpha}+\frac{\alpha}{D}\left(h_{T-1}-\delta h_{T}\right)
$$

If $h_{T-1}-\delta h_{T}>0$ this needs $r w_{T-1}>w_{T} \geq 0$ : no intercept.

If $h_{T-1}-\delta h_{T}<0$, then $r w_{T-1}<w_{T}$. In fact if $\left(K+w_{T}\right)^{\alpha}+\frac{\alpha}{D}\left(h_{T-1}-\delta h_{T}\right)<0$ there is no $w_{T-1} \geq 0$ giving indifference (because the LHS must be $\left.>0\right)$. But if $\left(\left(K+w_{T}\right)^{\alpha}+\frac{\alpha}{D}\left(h_{T-1}-\right.\right.$ $\left.\delta h_{T}\right)>0$ then we must have $w_{T}>\left[-\frac{\alpha}{D}\left(h_{T-1}-\delta h_{T}\right)\right]^{1 / \alpha}-K$. If $\left[-\frac{\alpha}{D}\left(h_{T-1}-\delta h_{T}\right)\right]^{1 / \alpha}-K>$ 0 this gives a positive lower bound on $\left(K+r w_{T-1}\right)^{\alpha}$ of (setting $\left.w_{T}=0\right), K^{\alpha}+\frac{\alpha}{D}\left(h_{T-1}-\delta h_{T}\right)$ which can be negative or positive. If $\left[-\frac{\alpha}{D}\left(h_{T-1}-\delta h_{T}\right)\right]^{1 / \alpha}-K<0$ the lower bound on $w_{T}$ is zero and then there is an intercept.
} 
Figure 1: Reservation wages which give indifference between pairs of maximal utility levels

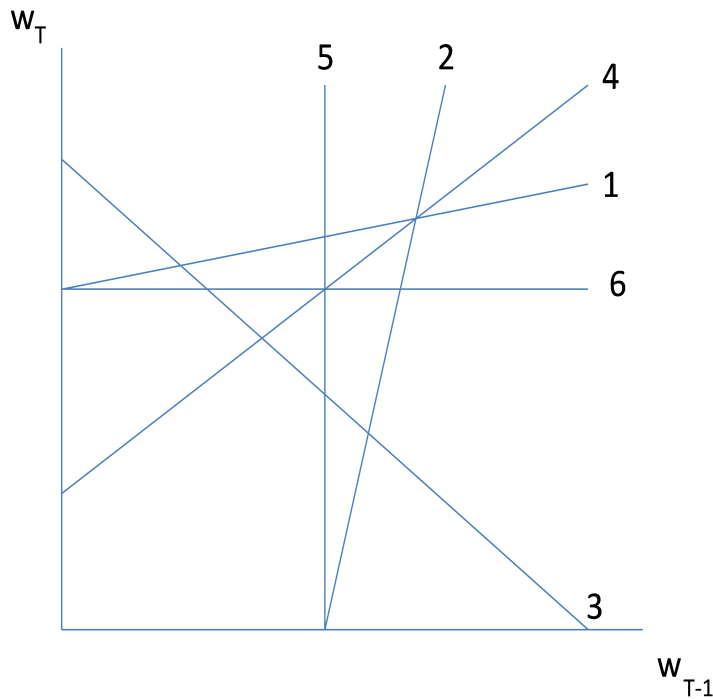

Figure 2: Optimal lifecycle participation profiles

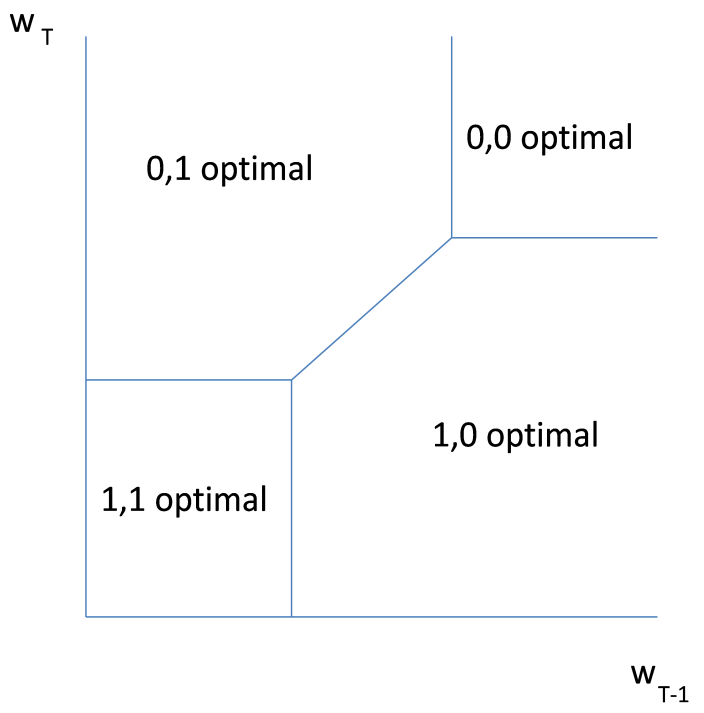


Figure 3: Increase in non-labour income $h_{T-1}<h_{T}$

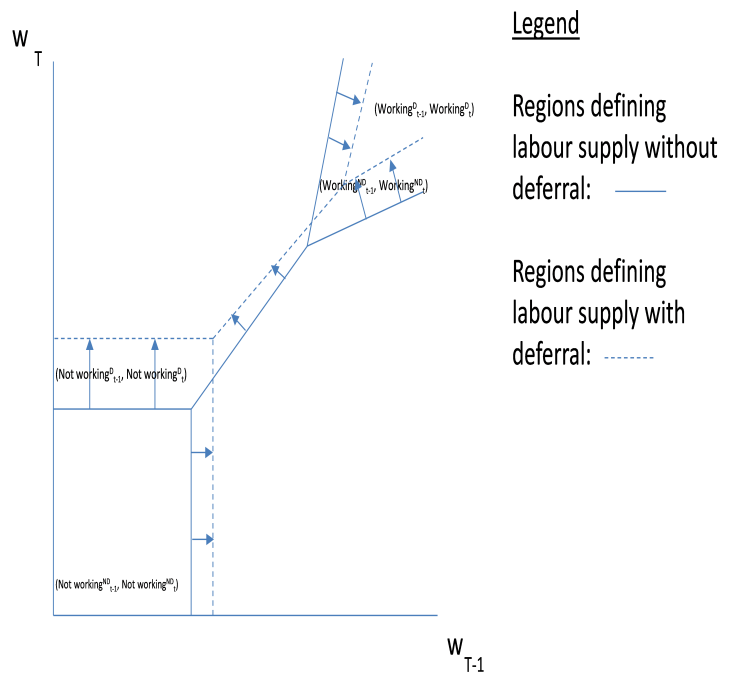

full time work only in $T$ (as in Figure 3). Conversely if the value of leisure is higher in $T-1$ than $T$, the wage region with full time work at $T$ expands at the expense of the wage region with full time work only in $T-1$ (as in Figure 4).

If the option to defer is suddenly introduced or taken up, or is made more generous, the present value of non-labour income increases. We can deduce the likely effects on lifecycle participation profiles. If leisure is more valuable in period $T-1$, the increase in $K$ will tend to reduce full time work in $T-1$. A proportion of those individuals who were working full time in both periods may switch to only working in period $T$ and some of those who previously only worked in $T-1$ may switch to only working in $T$. But some who previously only worked in $T$ may switch into inactivity in both periods. Thus with leisure more valuable in $T-1$, the increase in the value of the deferred pension unambiguously reduces the number of full time workers in $T-1$, but may raise or lower it in period $T$. If the value of leisure is higher in period $T$, the opposite effects occur: the number of full time workers in $T$ unambiguously falls while the number of full time workers in $T-1$ may fall or rise depending on the distribution of the lifecycle wages $w_{T-1}, w_{t}$ in the population.

The wealth change caused by deferral has participation effects on individuals close to the reservation wage in one period at least. However labour force participation is unaffected by the presence of pension deferral for those who earn sufficiently above the relevant critical wage defining full time work. In the next subsection we simulate the effect of pension deferral implied by our framework. 
Figure 4: Increase in non-labour income $h_{T-1}>h_{T}$

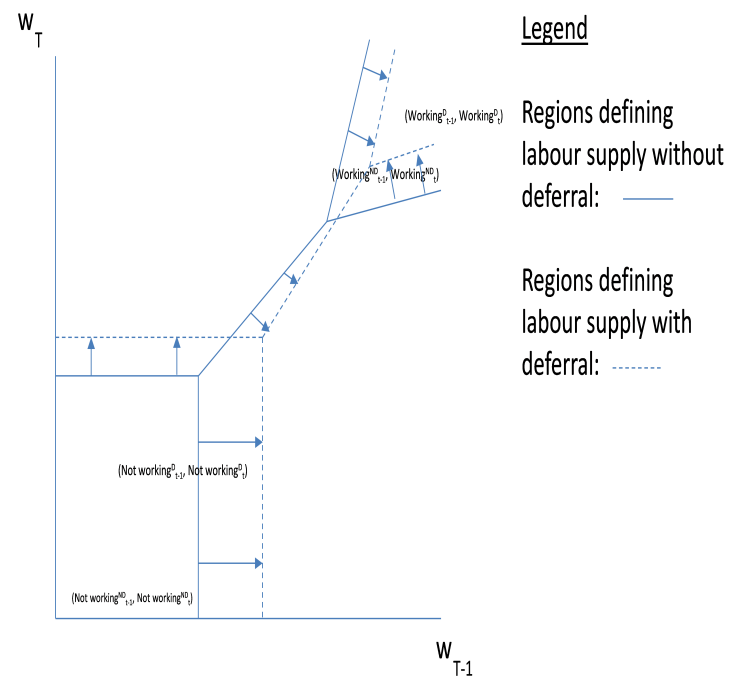

\subsubsection{Stylised simulation: defer or not defer?}

Having considered the theoretical effects of pension deferral within our framework, we demonstrate these effects using a numerical simulation. In order to calibrate our model we use a mixture of assumed parameters available in the literature and those inferred from secondary data.

Following the work of Attanasio et al. (2008) we set the relative risk parameter $\alpha$ to -0.5 . Using wave 4 (2012-2013) of the United Kingdom Household Longitudinal Survey we estimate median per capita (non-housing) wealth of $£ 1500$. Using the 2013-2014 UK Family Resources Survey (UKFRS) we estimate median weekly investment income (among individuals aged 65 and over) to be zero. The UKFRS also contains information on weekly private/occupational pension income, the median figure among all individuals aged 65 and over is $£ 32$. Finally we assume weekly state pension income to be $£ 125 .^{7}$ We also assume individuals work 40 hours per week, can earn an annual rate of return of $3 \%$ in the free market and have a time preference discount rate of 0.95 . If an individual defers their state pension they can earn an annual rate of return of 10.4 (equivalent to a weekly rate of $0.2 \%$ ), this is equal to the rate of return available to individuals under current government legislation. We set the marginal value of leisure $h$ in the penultimate period and terminal period at 0.006 and 0.00630 respectively (an increase of $5 \%$ between periods). ${ }^{8}$ In doing

\footnotetext{
${ }^{7}$ State pension income could also include benefits such as pension credit and other supplementary state benefit income sources.

${ }^{8}$ This value generates an optimal labour income/asset ratio of about $30 \%$, a reservation wage for zero work at a level similar to the UK Minimum Wage/ UK Living Wage and a
} 
Figure 5: Wage co-ordinates defining zero and full time work

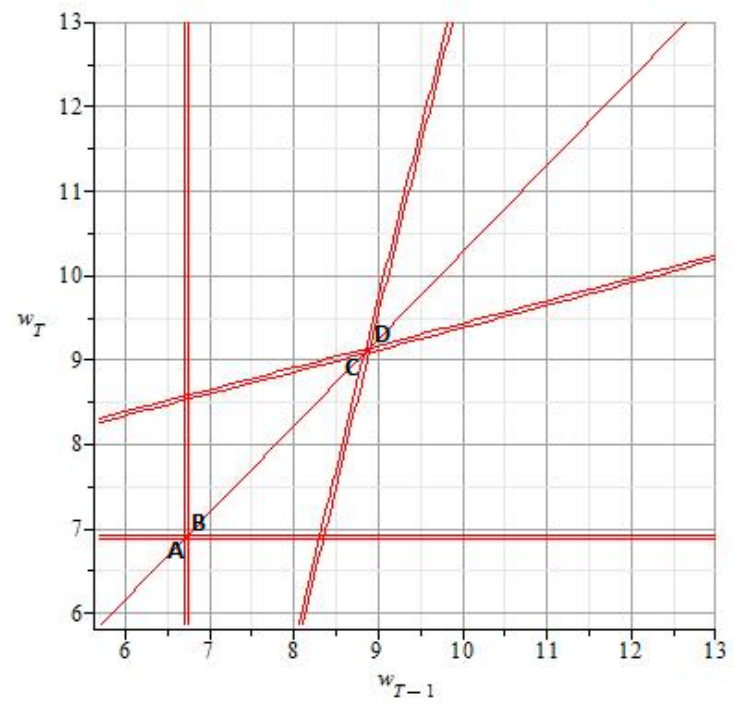

so we replicate the effects of Figure 3 more clearly i.e. assuming $h_{T-1}<\delta h_{T}$ as shown in Figure 5.

We provide a sketch of how the simulations are performed. First, we determine the wages defining indifference between the various labour supply regimes in (1) - (6) above. Next, using the assumed/inferred parameters we implicitly plot these indifferences, as shown in Figure 5. Our focus is on zero and full time work, therefore we compute the wage coordinates which correspond to these regimes being optimal. We carry out this exercise assuming no deferral and then repeat it assuming an individual does defer their state pension. We assume individuals defer their pension for one period and earn $10.4 \%$ rate of return on the missed state pension payment as per current UK legislation. In this way, we are able to plot the areas of different types of labour participation, with and without deferral, and hence show the effects of state pension deferral on labour supply.

By deferring one period the reservation wages required to be in a given labour supply regime increase in each period. In the case of zero work this is shown by the curves shifting from point $A$ to point $B$, whereas for full time work the corresponding loci shifts from point $C$ to point $D$. Under the no deferral option the wage rate required to be in zero work at $T-1, T$ is $(£ 6.69, £ 6.87)$ respectively, whilst under deferral it rises to $(£ 6.81, £ 6.99)$. Similarly for full time work at $(T-1, T)$ the corresponding wage rates are $(£ 9.07, £ 8.82)$, under deferral these increase to $(£ 9.25, £ 9.01)$. The effect of pension deferral therefore

critical wage for switching from part-time to full time of about one and a half times the National Minimum Wage. 
raises the full time reservation wage by around $2 \%$ assuming the above parameters. How sensitive are our results to changes in the assumed parameters? It turns out that the two parameters which change the critical wage combinations most significantly from the benchmark example above are $\alpha$, the coefficient of relative risk aversion and $h$ the marginal value of leisure in each period. Other parameters such as $A_{T-1}, y_{t-1}, y_{t}$ raise and lower the wage combinations in a predictable way, for example an increase $A_{t-1}$ will raise reservation wages for all labour supply combinations. That is to say, these parameters do not affect the shape of the wage curves as defined in Appendix C.

To demonstrate the sensitivity of our results, Table 1 shows the wage coordinates defining zero work in each period $\left(£ w_{T-1}^{11}, £ w_{T}^{11}\right)$ and the wage rate defining full time work $\left(£ w_{T-1}^{00}, £ w_{T}^{00}\right)$ when $\alpha$ and $h$ are (separately) altered from baseline (cases 1 and 4 in Table 1 refer to Figure 5). For each case note there are two rows, the top row refers to the situation where the individual does not defer their state pension and the second row refers to the situation when they do defer their state pension. The column $P V\left(£ Y^{*}\right)$ denotes the present value of total pension non-labour income (the sum of state and private pension); when an individual does not defer (the top row of each case) then $Y^{*}$ is equal to $£ 157$ in $\mathrm{T}-1$ and $\mathrm{T}$ (total: £314). If instead he/she chooses to defer then $Y^{*}$ is equal to $£ 32$ in $\mathrm{T}-1$ and $£ 307$ in $\mathrm{T}$ (total: $£ 339$ ). ${ }^{9}$ The present value of the two amounts (no defer and defer) is equal to $£ 309.4$ and $£ 330.05$ respectively therefore in every case the individual is better off deferring.

\footnotetext{
${ }^{9}$ These numbers are derived as follows: No deferral case $Y^{*}=$ weekly state pension $(£ 125)+$ weekly private pension (£32), which is equal to $£ 157$ in each period (total $£ 314$ ). In the defer case, $Y^{*}=$ weekly private pension $(£ 32)$ in $\mathrm{T}-1$ and then at $\mathrm{T}$ the individual receives their deferred state pension* $\left(1+r_{\text {defer }}\right)$ +weekly state pension + weekly private pension $(£ 32)$ (total £X).
} 
Table 1: Changes in $\alpha$ and $h$ on wage co-ordinates defining zero and full time work relative to Figure 5.

\begin{tabular}{|c|c|c|c|c|c|}
\hline Case & Defer? & $\alpha$ & $P V\left(£ Y^{*}\right)$ & $£ w_{T-1}^{11}, £ w_{T}^{11}$ & $£ w_{T-1}^{00}, £ w_{T}^{00}$ \\
\hline 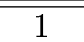 & No & -0.5 & 309.4 & $\begin{array}{c}6.69,6.87 \\
\end{array}$ & $99.07,8.82$ \\
\hline 1 & Yes & -0.5 & 330.05 & $6.81,6.99$ & $9.25,9.01$ \\
\hline 2 & No & -0.45 & 309.4 & $4.43,4.54$ & $5.34,5.20$ \\
\hline 2 & Yes & -0.45 & 330.05 & $4.50,4.62$ & $5.44,5.30$ \\
\hline 3 & No & -0.55 & 309.4 & $10.32,10.59$ & $18.40,17.90$ \\
\hline 3 & Yes & -0.55 & 330.05 & $10.51,10.80$ & $18.88,18.37$ \\
\hline \multicolumn{6}{|c|}{$h_{T-1}, h_{T}$} \\
\hline 4 & No & $0.006,0.0063$ & 309.4 & $6.69,6.87$ & $9.07,8.82$ \\
\hline 4 & Yes & $0.006,0.0063$ & 330.05 & $6.81,6.99$ & $9.25,9.01$ \\
\hline 5 & No & $0.008,0.0084$ & 309.4 & $9.26,9.50$ & $14.65,14.26$ \\
\hline 5 & Yes & $0.008,0.0084$ & 330.05 & $9.42,9.68$ & $14.99,14.58$ \\
\hline 6 & No & $0.004,0.0042$ & 309.4 & $4.31,4.42$ & $5.20,5.06$ \\
\hline 6 & Yes & $0.004,0.0042$ & 330.05 & $4.38,4.50$ & $5.30,5.16$ \\
\hline \multicolumn{6}{|c|}{ Tilting the marginal value of leisure in $T-1$ and $T$ (assuming $\alpha=0.5$ ) } \\
\hline \multicolumn{6}{|c|}{$\frac{h_{T-1}}{h_{T}}$} \\
\hline 7 & No & 0.95 & $0.006,0.0063$ & $6.69,6.87$ & $9.07,8.82$ \\
\hline 7 & Yes & 0.95 & $0.006,0.0063$ & $6.81,6.99$ & $9.25,9.01$ \\
\hline 8 & No & 1 & $0.006,0.006$ & $6.69,6.51$ & $8.56,8.70$ \\
\hline 8 & Yes & 1 & $0.006,0.006$ & $6.81,6.62$ & $8.73,8.88$ \\
\hline 9 & No & 1.05 & $0.0063,0.006$ & $6.69,6.15$ & $8.06,8.58$ \\
\hline 9 & Yes & 1.05 & $0.0063,0.006$ & $6.81,6.26$ & $8.21,8.75$ \\
\hline \multicolumn{6}{|c|}{$\begin{array}{l}\text { Notes:In cases 1-6 we assume } r_{\text {riskfree }}=1.03, r_{d e f e r}=1.104, \delta=0.95, A_{T-1}=1500, \\
\quad h_{T-1}=0.006, h_{T}=0.0063 \text { and individual works } 40 \text { hours per week. } Y \text { is defined } \\
\text { as the sum of non-pension investment income, private/occupational pension income } \\
\text { and state pension income. } w_{x}^{y} \text { corresponds to the wage in period } x \text { where } x \epsilon(T-1, T) \\
\text { and } y \text { corresponds to the labor supply regime where } y \epsilon(\text { nowork }(11) \text {, alwayswork }(00)) \text {. }\end{array}$} \\
\hline
\end{tabular}

Cases 1-3 of Table 1 shows how small changes in the coefficient of relative of risk aversion, $\alpha$, can significantly change the wage co-ordinates defining the reservation wages for zero and full time work. Case 2 in Table 1 indicates individuals who are less risk averse $(\alpha=-0.45)$ have a lower reservation wage relative to the benchmark $(\alpha=-0.5)$. On the other hand individuals who are more risk averse $(\alpha=-0.55)$ have a significantly higher reservation wage.

Now consider the effect of changing the marginal value of leisure, case 4 $\left(h_{T-1}=0.006, h_{T}=0.0063\right)$ is the benchmark case (demonstrated graphically in Figure 5). Increasing an individual's marginal value of leisure in each period (case 5: $\left(h_{T-1}=0.008, h_{T}=0.0084\right)$ ), intuitively should raise an individual's reservation wages for both not-working and working full time. Next, consider reducing an individual's marginal value of leisure (case 6: $\left(h_{T-1}=0.004, h_{T}=\right.$ $0.0042)$ ), this reduces an individual's reservation wage from the benchmark case. It is worth noting our benchmark example gives a zero work reservation wage close to UK National Minimum Wage and National Living Wage. Implicitly in 
the calibration the change in reservation wage on deferral is for deferral lasting one year.

Cases 7-9 analyse the effects of varying the ratio of the marginal value of leisure in $T-1$ and $T$. Case 7 is the benchmark case where the marginal value of leisure is higher in $\mathrm{T}$ than $\mathrm{T}-1$. In case 8 there is no change in the marginal value of leisure, consider the column showing the reservation wages for zero work ( $\left.£ w_{T-1}^{11}, £ w_{T}^{11}\right)$ the impact (relative to case 7 ) is that the period $\mathrm{T}$ wages for zero work are now lower (irrespective of whether an individual defers or not). Similarly the change in $\frac{h_{T-1}}{h_{T}}$ also affects the wage co-ordinates defining the full time reservation wages (see column $£ w_{T-1}^{00}, £ w_{T}^{00}$ ), in this case all the wage co-ordinates are lower than the benchmark example. Finally, in case 9 an individual's marginal value of leisure decreases between T-1 and T, similar to case 8 this reduces the reservation wage defining zero work in $\mathrm{T}$ and also the wage co-ordinates defining full time work (again, the direction of the effect is the same irrespective of whether an individual defers or not). A priori it is not clear how an individual's marginal value of leisure will evolve at or around SPA, for example it could be related to complementarities in leisure or exogenous shocks to one's health; however what is clear is that in a quasilinear framework as per (5) this parameter has important implications for the reservation wages defining zero and full time work.

It is important to note that the decision to defer state pension is optimal irrespective of changes to key parameters used in the simulation. Moreover, as the period of deferral increases beyond this, the reservation wage difference will rise. How the relative slopes of the participation regime boundaries and their position change principally depends on the change in the value of non-labour income by deferring and the difference in the marginal value of leisure in each period.

Empirical relevance of pension deferral. The stylised simulation showed that in the baseline example (case 1) deferral can affect labour supply decisions for all full time workers who earn more than approximately $£ 9$ per hour. We pool four waves of data from the Labour Force Survey between the years 2008 and 2013 to determine the wage distributions (conditional on being in work) for women aged between 60 and 65 , and men aged between 65 and $70{ }^{10}$ We restrict our sample to these age ranges as they cover the state retirement age and hence the period when individuals make the deferral decision. It is important to note that the decision to work and the deferral decision are independent (except for the implications on income tax). Our final sample consists of 483 individuals and Figures 6 and 7 depict their hourly wages.

It is clear that a significant proportion (around $54 \%$ of females and more than $62 \%$ males) in our sample earn more than $£ 9$ per hour, therefore deferral

\footnotetext{
${ }^{10}$ We ensure there is no overlap in the surveys to ensure our sample does not contain any repeated observations. We include individuals working below full time hours to boost sample size, noting that the mean wage for full time and part time workers in this age category are roughly equal.
} 
Figure 6: Female Wage Distribution: Ages 60-65 (2008-2013)

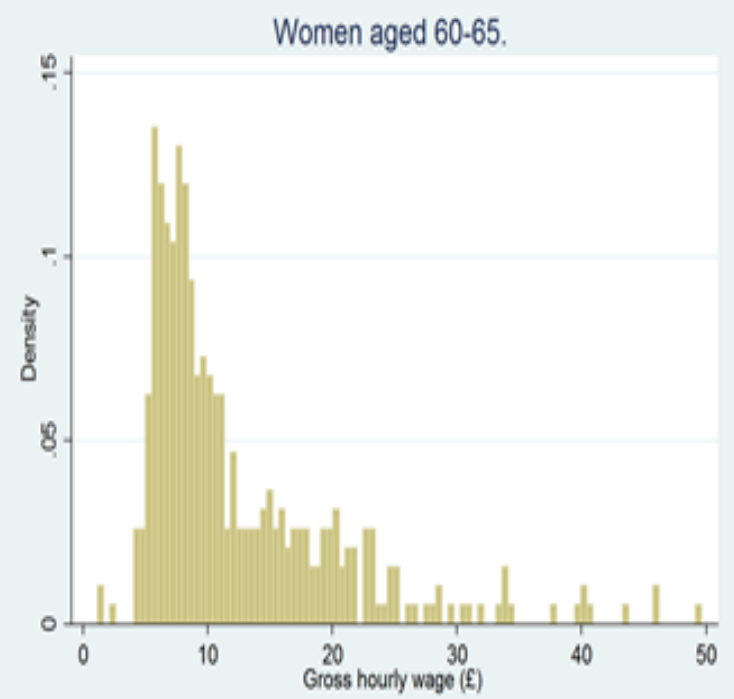

Figure 7: Male Wage Distribution: Ages 65-70 (2008-2013)

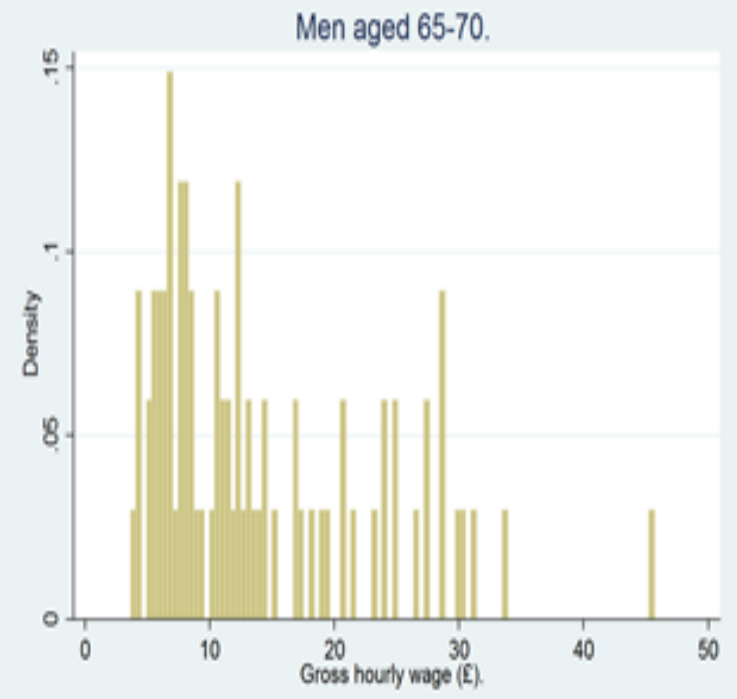


policy is an important component of the labour supply decision for a large proportion of older workers. Indeed a DWP report in 2008 suggested that individuals tend to coordinate their labour supply and deferral decision. They found $79 \%$ of deliberate deferrers were in paid work and tended to maintain their preretirement hours, primarily full time, after deferral. Family decisions were important so a partner continuing in work made deferral more likely, as did the desire to avoid liability for a higher income tax rate. Under current UK legislation there are actually different dimensions to the deferral choice: to opt for an enhanced weekly pension or a lump sum payment on undeferral and conditional on deciding to defer, for how long to do so. With a two period model these differences do not matter. But with increased longevity, deferral is increasingly common and so these details of the deferral scheme are important for both the government and the individual.

\section{UK State Pension \& Deferral.}

\subsection{Which Deferral Option is Best}

In a multiperiod setting the decision becomes one of choosing both if to defer and, if so, for how many years. In this section we simulate the present value of an individuals state pension pot at the date of undeferral, under both the incremental and lump sum option for deferral over a varying number of years. In our comparisons we purely compare deferral options based on the present net value under current government legislation, we do not use the theoretical framework developed in earlier sections of the paper.

On reaching SPA an individual can choose whether to take up the state pension or defer it from that date. They do not have to precommit to a length of deferral but at any future date can ask for their pension to start from then on. ${ }^{11}$ If an individual chooses to defer their pension, then current rules mean that for every five weeks an individual defers, their weekly State Pension increases by $1 \%$, this is equivalent to a $10.4 \%$ rate of return for each full year of deferral. Alternatively an individual may also defer their State Pension and receive a lump sum payment. ${ }^{12},{ }^{13}$ If an individual chooses to take the latter option, the lump sum they receive is the value of their past deferred weekly pension payments accumulated at an interest rate of at least $2 \%$ above the Bank of England

\footnotetext{
${ }^{11}$ This not true for the lump sum option, in which case the individual must defer for at least 52 weeks.

${ }^{12}$ Extra State Pension and lump sum payment are both taxed. In addition if you choose to defer then this will impact means tested benefits, whereas if you choose to recieve a lump sum, this will not affect certain means tested benefits.

${ }^{13}$ Since it's inception there have been various changes to legislation regarding how the rate of return on the deferral option is formulated, and the introduction of the lump sum option in 2006. For a more detailed description of these changes see Bozio et al (2010).
} 
base rate. ${ }^{14},{ }^{15}$ If an individual chooses to take the latter option, the lump sum they receive is the value of their past deferred weekly pension payments accumulated at an interest rate of at least $2 \%$ above the Bank of England base rate. ${ }^{16}$ Depending on the life expectancy of the individual there is no clear answer as to which option is more lucrative, however given the increasing life expectancy observed in the past 30 years, it is generally considered (see Farrar et al., 2012) that the incremental option offers a higher rate of return.

At the point of reinstatement of a deferred pension $S$, the present value of the extra weekly payment coming from the deferral is $x\left(1+1.01+1.01^{2}+. .1 .01^{\tau}\right)(1+$ $\left.(1+r)^{-1}+. .(1+r)^{T-S}\right)$ where $\tau$ is the number of months for which the pension has been deferred between SRA and age at $S, x$ is the original weekly pension payable at SRA, $r$ is a constant market interest rate and $T$ is the date of death. On the other hand the lump sum payable at $S$ is $x\left(1+1+\rho+(1+\rho)^{2}+. .(1+\rho)^{\tau}\right)$ where $\rho$ is at least $2 \%$ above bank base rate.

We plot the present value under each option in Figures 8 and 9 below. In Figure 8 we vary the generosity of the incremental option, i.e. the length of time it takes to earn a $1 \%$ increase in an individuals weekly state pension. Whilst in Figure 9 we vary the length of the period from the date of undeferral to death. It is these two factors which to a large extent dictate the PV of the deferred pension. To show this we set all other parameter values as follows: initial weekly state pension of $£ 125$, weekly interest rate on lump sum option equal to $\frac{0.05}{52}$, post undeferral weekly net rate of return equal to $\frac{0.02}{52}$ and deferral period equal to two years. We set the lump sum weekly interest rate equal to $\frac{0.05}{52}$ using the current policy rule that for the lump option of deferral, benefits will grow at $2 \%$ per annum above the Bank of England base rate. ${ }^{17}$

(i) Varying rate of return on incremental option Figure 8 shows the effect of changing the rate of return or relative generosity, assuming an individual lives for 15 years following the date of undeferral. The sloping curve represents the deferred income option whilst the flat curve corresponds to the lump sum option.

The break even of point for the $\mathrm{PV}$ of the pension is at a rate of return of about $1 \%$ for every 6.25 weeks deferred. Under existing rules the current rate of return is a $1 \%$ increment for every 5 weeks deferred, and therefore in this

\footnotetext{
${ }^{14}$ In terms of pension deferral one of the biggest changes of the move to a single tier pension is that the lump sum option will be scrapped and only the incremental option will be available to those who defer (White Paper 2013). Moreover the incremental option will become less generous providing deferrers with a rate of return of just under $5.8 \%$.

${ }^{15}$ Extra State Pension and lump sum payment are both taxed. In addition if you choose to defer then this will impact means tested benefits, whereas if you choose to recieve a lump sum, this will not affect certain means tested benefits.

${ }^{16}$ In terms of pension deferral one of the biggest changes of the move to a single tier pension is that the lump sum option will be scrapped and only the incremental option will be available to those who defer (White Paper 2013). At the time of writing the actual generosity of the incremental option is yet to be decided, however is believed to be in the region of half its current generosity (FT, September 2013).

${ }^{17}$ Bank of England historical data between 2005-2009 (prior to the financial crisis) reveals the average interest rate was roughly $3 \%$.
} 
Figure 8: Varying the contribution factor

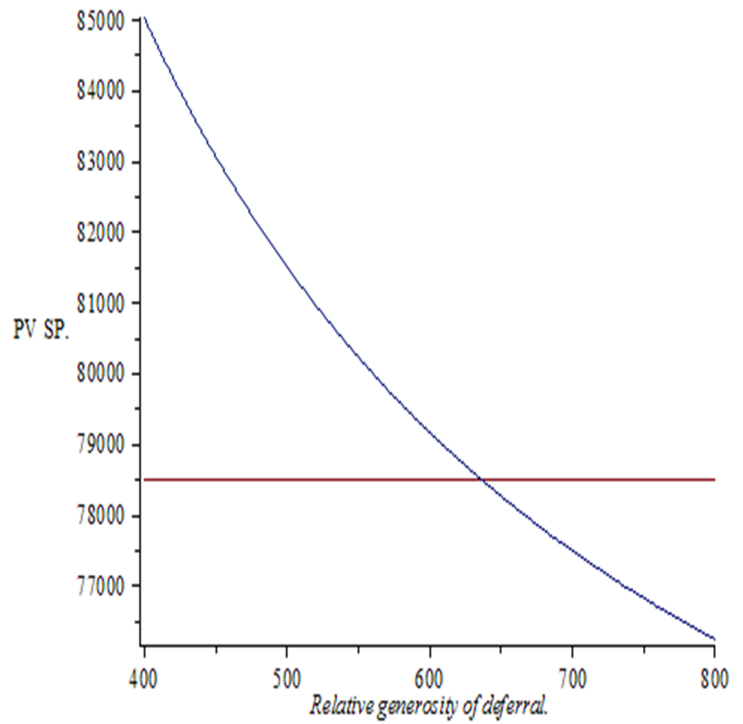

Notes: The X-axis measures the number of weeks (multiplied by 100) required for an individual to defer their state pension in order for them to receive an additional $£ 1$ extra a week upon undeferral.

example it is worth approximately $£ 3000$ to the individual to choose the deferred income option. However if the individual was credit constrained then it could be the case they require the lump sum to clear some debt, e.g. an outstanding mortgage. What is also clear is that during the 1970's when the contribution rate was approximately $1 \%$ for every $7-8$ weeks deferred, and individuals had a shorter life span (see Figure 10), the lump sum option would have been more lucrative had it been available. As of April 2016 the government plans to scrap the lump sum option and reduce the generosity of the incremental option by one-half which implies individuals will be worse off; however the proposed rate of return on the incremental option is still in excess of the free market rate.

(ii) Varying life span from undeferral date Figure 9 shows the effect of increasing longevity under the incremental option (green) and lump sum option (red), assuming parameters of the current legislation.

Intuitively, those who only live a short period after they undefer are much better off choosing the lump sum option. However it is clear that the deferred income option is more lucrative provided an individual lives for approximately 12 years or more after they undefer.

The Office for National Statistics (2011) published current and projected life expectancy tables by gender in the UK covering the period 1985 to 2035 . Over this period it is quite clear life expectancy has increased substantially, for both cohort and period groups. Period life expectancy refers to the life expectancy for 
Figure 9: Varying individuals life expectancy

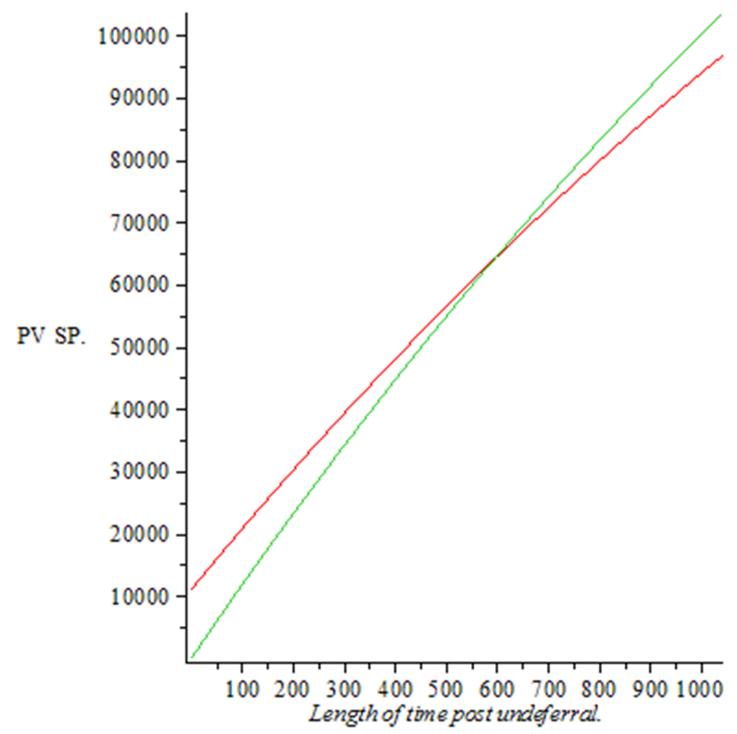

Notes: X-axis refers the duration (in weeks) of the deferral period.

those individuals in a given calender year (ONS, 2011). Hence in 2013 females are expected to live until 83 years of age on average. In contrast, cohort life expectancy at birth is calculated using age-specific mortality rates which allow for known or projected changes in mortality throughout a person's life (ONS, 2011). For example a female born in 2013 is expected to live until 94 years of age.

Supposing an individual reaches their life expectancy, Figure 10 implies the deferred income option is more lucrative for both current and future retirees, so long as the relative generosity of this option is not changed.

Farrar et al. (2012) compare the two undeferral options relative to not deferring and investing at the market rate, in most policy simulations deferral of any kind is preferred over non deferral. ${ }^{18}$ Similar to Disney and Smith (2002) and our own model, Farrar et al. (2012) assume individuals face no borrowing constraints. Deferral would not be optimal if individuals could not borrow against their future income. Assuming an individual reaches their predicted life expectancy, then our results imply the incremental option tends to offer a higher rate of return in most of the simulations. Similarly Farrar et al. (2012) find the $10.4 \%$ interest payment substantially exceeded the break even interest rate required for the incremental and lump sum option to be of equal value (in PV terms).

Coleman et al (2008) analyse the characteristics of deferrers versus those

\footnotetext{
${ }^{18}$ In their paper the authors worked in continuous time and do not consider a formal model of labour force participation.
} 
Figure 10: Cohort and period life expectancy men and women

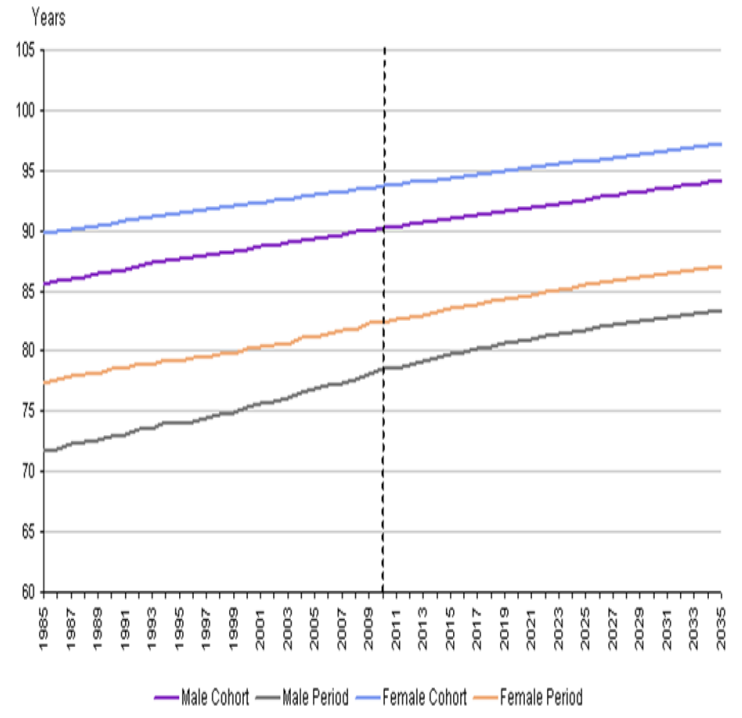

Source: ONS (2011)

who claim state pension at SPA. Their results suggest deferrers are mainly high earners who had good financial knowledge of the deferral option (hence the majority of them chose the deferred income option) and either they or their partner tended to continue engaging with paid work post SPA. These individuals reported they were financially comfortable during the deferral period. This suggests the employment and deferral decision may well be jointly determined and it is unlikely deferrers are from credit constrained households. More recent data from waves four and five of the English Longitudinal Study of Ageing (ELSA) spanning the years 2008-2013 also contain information on state pension deferral, despite small sample sizes those who do defer tend to have worked in professional, managerial or skilled non-manual occupations. These individuals are more likely to choose the incremental income option and tend to defer their state pension for between 1 and 5 years. ${ }^{19}$

\subsection{Prevalence of pension deferral.}

A Freedom of Information Request released by the DWP showed between September 2009-2010 approximately 66,300 individuals deferred their pension. ${ }^{20}$ Of this total roughly just over one third took the increment option, whilst nearly half

\footnotetext{
${ }^{19}$ Occupation data is fed forward to wave one of ELSA from the Health Survey for England data, from which the original ELSA sample is derived.

${ }^{20}$ Freedom of Information request catalogue number $(2773 / 2011)$.
} 
took the lump sum option, the remainder took a mixture of the two. ${ }^{21}$ Of the total number of individuals eligible to claim their state pension, roughly 1 in 10 chose to defer their pension. Coleman et al (2008) using administrative data surveyed individuals who were approaching or had reached SPA, and found only a low level of respondents, $65 \%$, knew of the option to defer. This proportion only increased slightly after SPA. The main reasons cited were due time constraints and it being the 'spouses responsibility', lack of interest or confidence in financial matters. Therefore despite roughly 1 in 10 individuals deferring it is likely with increased awareness (a central aim of the 2013 White Paper) this proportion will rise..$^{22}$

\section{Conclusion and policy implications}

In this paper we develop a lifecycle framework to model the joint decision of pension deferral and intertemporal labour supply. Contrary to the policy aim of pension deferral which is to extend working lives, our theoretical model indicates pension deferral acts to raise the reservation wage and reduce the likelihood of labour force participation. The exact direction in which labour force changes in a two period framework depends on the marginal value of leisure in each period and its change over time. There are clear qualitative effects, depending on wage profile, non-labour wealth and preferences, introduction of a pension deferral scheme can tilt labour participation towards the present or future.

Our numerical simulation and empirical evidence suggest that the deferral policy affects a large proportion of the older working population. As a ballpark figure the option changes the reservation wages by about $2 \%$. Moreover similarly to Farrar et al. (2012) our results indicate (1) pension deferral is optimal in the absence of credit constraints and (2) of the deferral options available, the incremental income option is more lucrative.

The recent UK announcement of a move to a single tier pension system will have a number of financial implications for those approaching retirement and future generations (Crawford et al., 2013). This includes changes to the rules governing pension deferral, the most significant of which relate to the abolition of the lump sum option and reduction in the generosity of the incremental option (the implied annual interest rate on deferrals will halve from $10.4 \%$ to $5.8 \%$ ). Nonetheless this is still far in excess of other tax efficient financial products commonly available, including the Pensioner Bond launched in December 2014.

\footnotetext{
${ }^{21}$ FOI DWP (2011) pp.2 notes: New rules for deferral came into effect in April 2005 and lump payments became available from April 2006. A person who deferred their State Pension before April 2005 would qualify for increments for the period up to April 2005 and may have a choice of either a lump sum payment or an increment for the period of deferral from April 2005. This means some people may have both an increment and a lump sum payment. The lump sum option is only available to those who have deferred continuously for at least 12 months. The numbers do not include those who deferred for less than 12 months and opted for simple arrears instead of increments.

${ }^{22}$ Options to allow increased flexibility of deferring and undefering multiple times are also being considered by the DWP (White Paper 2013).
} 
At present one in ten retirees chooses to defer their state pension; policymakers are attempting to design various initiatives to extend working lives in the face of increasing life expectancy. Therefore research which attempts to understand the effects of pension deferral from a theoretical and empirical viewpoint is of paramount importance.

We have simplified the framework to highlight the key factors. Of course relevant extensions are possible. Above we have considered a single individuals choice. In the aggregate any change in total pension cost to the government would have to be financed, it could thus go hand in hand with a wage tax on all workers both elderly and others. If deferral is less costly to the exchequer then the wage tax could be lower and consequently the regions in which wages are above their reservation levels might expand. Moreover if there are many individuals who all choose to defer and this reduces their labour supply, then through the fall in aggregate labour supply, worker productivity and so pretax wage rates could rise. We have simplified away these feedback effects.

Another relationship we have not considered is the established link between health and age. If in poor health at $\mathrm{T}-1$, the demand for lesiure and conmsumption at T-1 is likley to increase making deferral less likely. On the other hand if in good health at T-1 but with the risk of facing poor health at $\mathrm{T}$ and its associated expenses, the demand for leisure and consumption at T-1 may fall and that for deferral increase. Therefore the net effect on labour supply is ambigious.

Finally we have assumed uncertainty away. This could impact through several channels: the life expectancy, the future non-labour income and the future wage rate.

\section{Acknowledgements}

The authors would like to thank participants at the following events: Work Pensions Economics Group (University of Sheffield) Annual conference 2013 and Netspar summer International Pension Workshop 2014 (Venice International University).

\section{References}

[1] Orazio Attanasio \& Hamish Low \& Virginia Sanchez-Marcos. 2008. Explaining Changes in Female Labor Supply in a Life-Cycle Model. American Economic Review, American Economic Association, vol. 98(4), pages 151752 , September.

[2] Banks, James and Smith, Sarah. (2006). Retirement in the UK. Oxford Review of Economic Policy, 22(1), 40-56. 
[3] Blau David M. 2012. Pensions, Household Saving, and Welfare: A Dynamic Analysis. IZA Discussion Papers 5554, Institute for the Study of Labor (IZA).

[4] Bloom, David E., David Canning, and Michael Moore. 2014. Optimal retirement with increasing longevity. The Scandinavian journal of economics 116 , no. $3,838-858$.

[5] Bozio Antoine, Crawford Rowena \& Tetlow Gemma. 2010. The History of State Pensions in the UK: 1948 to 2010. IFS Briefing Note BN105, Institute for Fiscal Studies.

[6] Coleman Nick, McLeod Rosie, Norden Oliver and Coulter Alice. 2008. State Pension deferral: public awareness and attitudes. Research Report No 526. Department for Work and Pensions.

[7] Crawford Rowena, Keynes Soumaya \& Tetlow Gemma. 2013. A single-tier pension: what does it really mean? IFS Report 82.

[8] Crawford, R., O'Dea, C. 2014. Cash and Pensions: Have the elderly in England saved optimally for retirement. IFS working paper (W14/22).

[9] Crook, J. (2006). Household debt demand and supply: A cross-country comparison. The economics of consumer credit, 63-92.

[10] Curme, M. A., \& Even, W. E. (1995). Pension coverage and borrowing constraints. Journal of Human Resources, 701-712.

[11] Disney Richard and Smith Sarah. 2002. The Labour Supply Effect of the Abolition of the Earnings Rule for Older Workers in the United Kingdom. The Economic Journal, 112: C136-C152.

[12] Department for Work and Pensions. 2013. White Paper: The single-tier pension: a simple foundation for saving. Department for Work and Pensions.

[13] Farrar Sue, Moizer Jonathon and Hyde Mark. 2012. The value of incentives to defer the UK state pension. Pensions 17, 46-62.

[14] Gustman Alan L. \& Steinmeier Thomas L. 2002. Retirement and the Stock Market Bubble. NBER Working Papers 9404, National Bureau of Economic Research, Inc.

[15] Le Blanc, J., Porpiglia, A., Teppa, F., Zhu, J., \& Ziegelmeyer, M. (2014). Household saving behaviour and credit constraints in the Euro area (No. 428). Netherlands Central Bank, Research Department.

[16] Meghir, Costas and Whitehouse, Edward. (1997). Labour market transitions and retirement of men in the UK. Journal of Econometrics, 79(2), 327-354. 
[17] Office for National Statistics. 2011. 2010-based Period and Cohort Life Expectancy tables. Link: http://www.ons.gov.uk/ons/rel/lifetables/periodand-cohort-life-expectancy-tables /2010-based/p-and-c-le.html

[18] Scholz, J. K., Seshadri, A., and Khitatrakun, S. (2004). Are americans saving" optimally" for retirement? (No. w10260). National Bureau of Economic Research.

[19] Stokey, N. L., Lucas Jr, R. E., and Prescott, E. C. (1989). Recursive Methods in Economic Dynamics. Harvard University Press, Cambridge.

[20] Thurley Dunje. 2010. Deferred Retirement Increments. Business and Transportation Section, Library, House of Commons.

[21] Wolff, E. N. (1998). Recent trends in the size distribution of household wealth. The Journal of Economic Perspectives, 131-150. 


\section{A The Semi-Indirect Utility Function for Quasilinear- Isoelastic Preferences}

Defining $A_{T}$ as the financial wealth carried forward from period $T-1$ to period $T$, we can substitute out the lifetime budget constraint to write $c_{T-1}$ in terms of initial wealth minus savings and leave the problem

$$
\begin{gathered}
U=\frac{\left(A_{T-1}+y_{T-1}+w_{T-1}\left(1-L_{T-1}\right)-A_{T}\right)^{\alpha}}{\alpha}+h_{T-1} L_{T-1} \\
+\delta\left(\frac{\left(r A_{T}+y_{T}+w_{T}\left(1-L_{T}\right)\right)^{\alpha}}{\alpha}+h_{T} L_{T}\right)
\end{gathered}
$$

Maximising $U$ wrt $A_{T}$ gives

$$
A_{T}=\frac{x_{T-1}-(\delta r)^{1 /(\alpha-1)}\left(y_{T}+w_{T}\left(1-L_{T}\right)\right.}{1+r(\delta r)^{1 /(\alpha-1)}}
$$

where $x_{T-1}=A_{T-1}+y_{T-1}+w_{T-1}\left(1-L_{T-1}\right)$ and putting this back into $U$ gives

$$
\begin{aligned}
U= & \frac{\left(A_{T-1}+y_{T-1}+w_{T-1}\left(1-L_{T-1}\right)-\left[\frac{x_{T-1}-(\delta r)^{1 /(\alpha-1)}\left(y_{T}+w_{T}\left(1-L_{T}\right)\right.}{1+r(\delta r)^{1 /(\alpha-1)}}\right]\right)^{\alpha}}{\alpha}+h_{T-1} L_{T-1} \\
& +\delta\left(\frac{\left(r\left[\frac{x_{T-1}-(\delta r)^{1 /(\alpha-1)}\left(y_{T}+w_{T}\left(1-L_{T}\right)\right.}{1+r(\delta r)^{1 /(\alpha-1)}}\right]+y_{T}+w_{T}\left(1-L_{T}\right)\right)^{\alpha}}{\alpha}+h_{T} L_{T}\right)
\end{aligned}
$$

The semi indirect utility function is then

$$
v=\frac{\left(r\left(A_{T-1}+y_{T-1}+w_{T-1}\left(1-L_{T-1}\right)\right)+y_{T}+w_{T}\left(1-L_{T}\right)\right)^{\alpha}}{\alpha}\left((\delta r)^{\alpha /(\alpha-1)}+\delta\right)
$$

which can be rewritten as

$$
v=\frac{\left.\left(K^{s}+r w_{T-1}\left(1-L_{T-1}\right)\right)+w_{T}\left(1-L_{T}\right)\right)^{\alpha}}{\alpha} D+h_{T-1} L_{T-1}+\delta h_{T} L_{T}
$$

where:

$$
K=r\left(A_{T-1}+y_{T-1}\right)+y_{T}, D=\left((\delta r)^{\alpha /(\alpha-1)}+\delta\right)
$$




\section{B Leisure Demands with Continuous Hours}

Consider the value function assuming a quasilinear specification for utility:

$$
\begin{aligned}
v & =\frac{1}{\alpha}\left[K^{s}+w_{T-1}\left(1-L_{T-1}\right)+\frac{w_{T}}{r}\left(1-L_{T}\right)\right]^{\alpha} D+h_{T-1} L_{T-1}+\delta h_{T} L_{T} \\
D & =\left((\delta r)^{\alpha /(\alpha-1)}+\delta\right.
\end{aligned}
$$

First order conditions wrt $L_{T-1}, L_{T}$ are

$$
\begin{aligned}
& \frac{\partial v}{\partial L_{T-1}}=h_{T-1}-D w_{T-1}\left[K^{s}+w_{T-1}\left(1-L_{T-1}\right)+\frac{w_{T}}{r}\left(1-L_{T}\right)\right]^{\alpha-1} \\
& \frac{\partial v}{\partial L_{T-1}}=h_{T}-D \frac{w_{T}}{r}\left[K^{s}+\frac{w_{T}}{r}\left(1-L_{T-1}\right)+\frac{w_{T}}{r}\left(1-L_{T}\right)\right]^{\alpha-1}
\end{aligned}
$$

which can be written

$$
\begin{aligned}
& \frac{\partial v}{\partial L_{T-1}}:\left(\frac{h_{T-1}}{D w_{T-1}}\right)^{1 /(\alpha-1)}-\left[K^{s}+w_{T-1}\left(1-L_{T-1}\right)+\frac{w_{T}}{r}\left(1-L_{T}\right)\right] \\
& \frac{\partial v}{\partial L_{T-1}}:\left(\frac{r \delta h_{T}}{D w_{T}}\right)^{1 /(\alpha-1)}-\left[K^{s}+w_{T-1}\left(1-L_{T-1}\right)+\frac{w_{T}}{r}\left(1-L_{T}\right)\right]
\end{aligned}
$$

We have the constraints $0 \leq L_{t} \leq 1, t=T-1, T$. The combinations of possible solutions are

(1) if $\left(K^{s}+w_{T-1}+\frac{w_{T}}{r}\right)^{\alpha-1}<\left(\frac{h_{T-1}}{D w_{T-1}}\right)$ and $\left(K^{s}+w_{T-1}+\frac{w_{T}}{r}\right)^{\alpha-1}<\left(\frac{r \delta h_{T}}{D w_{T}}\right)$, at zero leisure each period the marginal utility of leisure exceeds the marginal utility of consumption so optimally $\left(L_{T-1}, L_{T}\right)=(0,0)$

(2) if

$$
\left(K^{s}\right)^{\alpha-1}<\left(\frac{h_{T-1}}{D w_{T-1}}\right) \text { and }\left(K^{s}\right)^{\alpha-1}<\left(\frac{r \delta h_{T}}{D w_{T}}\right)
$$

(at zero work marginal utility of consumption still less than marginal utility of leisure) so optimally $\left(L_{T-1}, L_{T}\right)=(1,1)$

(3) If

$$
\left(K^{s}+w_{T-1}\right)^{\alpha-1}>\left(\frac{h_{T-1}}{D w_{T-1}}\right) \text { and }\left(K^{s}+w_{T-1}\right)^{\alpha-1}<\left(\frac{r \delta h_{T}}{D w_{T}}\right)
$$

(with full time work in $T-1$ and zero work at $T$, at $T-1$ the marginal utility of consumption exceeds that of leisure but at $T$ the reverse holds) so $\left(L_{T-1}, L_{T}\right)=$ $\left(L_{T-1}, L_{T}\right)=(0,1)$ must be optimal

(4) If

$$
\left(K^{s}+\frac{w_{T}}{r}\right)^{\alpha-1}<\left(\frac{h_{T-1}}{D w_{T-1}}\right) \text { and }\left(K^{s}+\frac{w_{T}}{r}\right)^{\alpha-1}>\left(\frac{r \delta h_{T}}{D w_{T}}\right)
$$

(with full time work in $T$ and zero work at $T-1$, at $T-1$ the marginal utility of leisure exceeds that of consumption at $T-1$, but at $T$ the reverse holds) so $\left(L_{T-1}, L_{T}\right)=(1,0)$ must be optimal 
(5) if

$$
K^{s}<\left(\frac{r \delta h_{T}}{D w_{T}}\right)^{1 /(\alpha-1)}<K^{s}+\frac{w_{T}}{r},\left(\frac{r \delta h_{T}}{w_{T}}\right)<\left(\frac{h_{T-1}}{w_{T-1}}\right)
$$

then

$$
L_{T}=\frac{r K^{s}}{w_{T}}+1-\left(\frac{\delta h_{T}}{D}\right)^{1 /(\alpha-1)}\left(\frac{r}{w_{T}}\right)^{\alpha /(\alpha-1)}
$$

satisfies $0<L_{T}<1$ and

$$
\left(K^{s}+\frac{w_{T}}{r}\left(1-L_{T}\right)\right)^{\alpha-1}<\left(\frac{h_{T-1}}{D w_{T-1}}\right),\left(K^{s}+\frac{w_{T}}{r}\left(1-L_{T}\right)\right)^{\alpha-1}=\left(\frac{r \delta h_{T}}{D w_{T}}\right)
$$

The optimum is $\left(L_{T-1}, L_{T}\right)=\left(1, \frac{r K^{s}}{w_{T}}+1-\left(\frac{\delta h_{T}}{D}\right)^{1 /(\alpha-1)}\left(\frac{r}{w_{T}}\right)^{\alpha /(\alpha-1)}\right)$

(6) if

$$
K^{s}+w_{T-1}<\left(\frac{r \delta h_{T}}{D w_{T}}\right)^{1 /(\alpha-1)}<K^{s}+w_{T-1}+\frac{w_{T}}{r},\left(\frac{h_{T-1}}{w_{T-1}}\right)<\left(\frac{r \delta h_{T}}{w_{T}}\right)
$$

then

$$
L_{T}=\frac{r K^{s}+w_{T-1}}{w_{T}}+1-\left(\frac{\delta h_{T}}{D}\right)^{1 /(\alpha-1)}\left(\frac{r}{w_{T}}\right)^{\alpha /(\alpha-1)}
$$

satisfies $0<L_{T}<1$ and

$$
\left(K^{s}+w_{T-1}+\frac{w_{T}}{r}\left(1-L_{T}\right)\right)^{\alpha-1}>\left(\frac{h_{T-1}}{D w_{T-1}}\right),\left(K^{s}+w_{T-1}+\frac{w_{T}}{r}\left(1-L_{T}\right)\right)^{\alpha-1}=\left(\frac{r \delta h_{T}}{D w_{T}}\right)
$$

The optimum is $\left(L_{T-1}, L_{T}\right)=\left(0, \frac{r K^{s}}{w_{T}}+1-\left(\frac{\delta h_{T}}{D}\right)^{1 /(\alpha-1)}\left(\frac{r}{w_{T}}\right)^{\alpha /(\alpha-1)}\right)$

(7) if

$$
K^{s}<\left(\frac{h_{T-1}}{D w_{T-1}}\right)^{1 /(\alpha-1)}<K^{s}+w_{T-1},\left(\frac{h_{T-1}}{w_{T-1}}\right)<\left(\frac{r \delta h_{T}}{w_{T}}\right)
$$

then

$$
L_{T-1}=\left[K^{s}+w_{T-1}-\left(\frac{h_{T-1}}{D w_{T-1}}\right)^{1 /(\alpha-1)}\right] \frac{1}{w_{T-1}}
$$

satisfies $0<L_{T-1}<1$ and

$$
\left(K^{s}+w_{T-1}\left(1-L_{T-1}\right)\right)^{\alpha-1}=\left(\frac{h_{T-1}}{D w_{T-1}}\right),\left(K^{s}+w_{T-1}\left(1-L_{T-1}\right)\right)^{\alpha-1}<\left(\frac{r \delta h_{T}}{D w_{T}}\right)
$$

(8) if

$$
K^{s}+\frac{w_{T}}{r}<\left(\frac{h_{T-1}}{D w_{T-1}}\right)^{1 /(\alpha-1)}<K^{s}+w_{T-1}+\frac{w_{T}}{r},\left(\frac{h_{T-1}}{w_{T-1}}\right)>\left(\frac{r \delta h_{T}}{w_{T}}\right)
$$

then

$$
L_{T-1}=\left[K^{s}+w_{T-1}+\frac{w_{T}}{r}-\left(\frac{h_{T-1}}{D w_{T-1}}\right)^{1 /(\alpha-1)}\right] \frac{1}{w_{T-1}}
$$


satisfies $0<L_{T-1}<1$ and

$$
\begin{gathered}
\left(K^{s}+w_{T-1}\left(1-L_{T-1}\right)+\frac{w_{T}}{r}\right)^{\alpha-1}=\left(\frac{h_{T-1}}{D w_{T-1}}\right),\left(K^{s}+w_{T-1}\left(1-L_{T-1}\right)+\frac{w_{T}}{r}\right)^{\alpha-1}>\left(\frac{r \delta h_{T}}{D w_{T}}\right) \\
(9) \text { if }\left(\frac{h_{T-1}}{w_{T-1}}\right)^{1 /(\alpha-1)}=\left(\frac{r \delta h_{T}}{D w_{T}}\right)^{1 /(\alpha-1)} \text { and } \\
{\left[K^{s}+w_{T-1}+\frac{w_{T}}{r}\right]^{\alpha-1}<\left(\frac{h_{T-1}}{D w_{T-1}}\right)<\left[K^{s}\right]^{\alpha-1}}
\end{gathered}
$$

optimally both lesiures are interior and any combination of $0, L_{T-1}, L_{T}<1$ on the line

$$
w_{T-1}\left(1-L_{T-1}\right)+\frac{w_{T}}{r}\left(1-L_{T}\right)=\left(\frac{h_{T-1}}{D w_{T-1}}\right)^{1 /(\alpha-1)} K^{s}
$$

are optimal. 


\section{The Wage Profiles Giving Indifferent Partici- pation Profiles}

Each pairwise utility combination is defined as follows:

(i) $v_{00}=v_{01}$

$$
\begin{aligned}
\left(K^{s}+r w_{T-1}^{s}+w_{T}^{s}\right)^{\alpha} & =\left(K^{s}+r w_{T-1}^{s}\right)^{\alpha}+\frac{\alpha}{D} \delta h_{T} \\
w_{T}^{s, 1} & =\left(\left(K^{s}+r w_{T-1}^{s, 1}\right)^{\alpha}+\frac{\alpha}{D} \delta h_{T}\right)^{1 / \alpha}-K^{s}-r w_{T-1}^{s, 1}
\end{aligned}
$$

(ii) $v_{00}=v_{10}$

$$
\begin{aligned}
\frac{\left(K^{s}+r w_{T-1}^{s}+w_{T}^{s}\right)^{\alpha}}{\alpha} D & =\frac{\left(K^{s}+{ }^{s} w_{T}\right)^{\alpha}}{\alpha} D+h_{T-1} \\
r w_{T-1}^{s, 2} & =\left(\left(K^{s}+w_{T}^{2}\right)^{\alpha}+\frac{\alpha}{D} h_{T-1}\right)^{1 / \alpha}-K^{s}-w_{T}^{s, 2}
\end{aligned}
$$

(iii) $v_{00}=v_{11}$

$$
\begin{aligned}
\frac{\left(K^{s}+r w_{T-1}^{s}+w_{T}^{s}\right)^{\alpha}}{\alpha} D & =\frac{K^{s, \alpha}}{\alpha} D+h_{T-1}+\delta h_{T} \\
r w_{T-1}^{s, 3}+w_{T}^{s, 3} & =\left(K^{s, \alpha}+\frac{\alpha}{D}\left(h_{T-1}+\delta h_{T}\right)\right)^{1 / \alpha}-K^{s}
\end{aligned}
$$

(iv) $v_{01}=v_{10}$

$$
\begin{aligned}
\left(K^{s}+r w_{T-1}^{4}\right)^{\alpha} & =\left(K^{s}+w_{T}^{4}\right)^{\alpha}+\frac{\alpha}{D}\left(h_{T-1}-\delta h_{T}\right) \\
r w_{T-1}^{s, 4} & =\left(\left(K^{s}+w_{T}^{s, 4}\right)^{\alpha}+\frac{\alpha}{D}\left(h_{T-1}-\delta h_{T}\right)\right)^{1 / \alpha}-K^{s}
\end{aligned}
$$

(v) $v_{01}=v_{11}$

$$
r w_{T-1}^{s, 5}=\left(K^{s, \alpha}+\frac{\alpha}{D} h_{T-1}\right)^{1 / \alpha}-K^{s}
$$

(vi) $v_{10}=v_{11}$

$$
w_{T}^{s, 6}=\left(K^{s, \alpha}+\frac{\alpha}{D} \delta h_{T}\right)^{1 / \alpha}-K^{s}
$$

Where $s=n d, d$.

For convenience we repeat the indifference relations here, but setting wages 
on the RHS to zero in order to calculate the relevant wage intercepts

$$
\begin{aligned}
& (1)=V_{00}^{s}-V_{01}^{s}: w_{T}^{s, 1}=\left(K^{s, \alpha}+\frac{\alpha}{D} \delta h_{T}\right)^{1 / \alpha}-K^{s} \\
& (2)=V_{00}^{s}-V_{10}^{s}: r w_{T-1}^{s, 2}=\left(K^{s, \alpha}+\frac{\alpha}{D} h_{T-1}\right)^{1 / \alpha}-K^{s} \\
& (3)=V_{00}^{s}-V_{11}^{s}: r w_{T-1}^{s, 3}+w_{T}^{3}=\left(K^{s, \alpha}+\frac{\alpha}{D}\left(h_{T-1}+\delta h_{T}\right)\right)^{1 / \alpha}-K^{s} \\
& (4)=V_{10}^{s}-V_{01}^{s}: r w_{T-1}^{s, 4}=\left(K^{s, \alpha}+\frac{\alpha}{D}\left(h_{T-1}-\delta h_{T}\right)\right)^{1 / \alpha}-K^{s} \\
& (5)=V_{11}^{s}-V_{01}^{s}: r w_{T-1}^{s, 5}=\left(K^{s, \alpha}+\frac{\alpha}{D} h_{T-1}\right)^{1 / \alpha}-K^{s} \\
& (6)=V_{10}^{s}-V_{11}^{s}: w_{T}^{s, 6}=\left(K^{s, \alpha}+\frac{\alpha}{D} \delta h_{T}\right)^{1 / \alpha}-K^{s}
\end{aligned}
$$

Comparing the intercept of the loci: those of (1) and (6) are equal as are those of (2) and (5). But the intercept of locus (1) is below that of locus(3) on the $w_{T}^{s}$ axis , and of locus (2) is below that of locus (3) on the $w_{T-1}^{s}$ axis. Combining this information gives Figure 1 in the text.

Comparing the loci we see that for wages such that $V_{10}^{s}=V_{01}^{s}$ and $V_{00}^{s}=V_{01}^{s}$ we must also have $V_{00}^{s}=V_{10}^{s}$, in terms of Figure 1 the loci (1), (2) must cross each other on the locus (4). Similarly the loci (5), (6) $\left(V_{11}^{s}=V_{01}^{s}\right.$ and $\left.V_{11}^{s}=V_{10}^{s}\right)$ must cross on the locus (4) $\left(V_{01}^{s}=V_{10}^{s}\right)$. For similar reasons loci (1), (3), (5) must intersect at a common point; and so must loci (2), (3), (6).

The indifference relations $V_{11}^{s}=V_{01}^{s}, V_{11}^{s}=V_{10}^{s}$ and $V_{00}^{s}=V_{11}^{s}$ are all linear in the wage rates with the last being negatively sloped and the other two respectively horizontal and vertical. Relation (4), (1) and (2); $V_{10}^{s}=V_{01}^{s}, V_{00}^{s}=V_{01}^{s}$ and $V_{00}^{s}=V_{10}^{s}$ respectively are all positively sloped. For example differentiating $v_{00}-v_{01}$ implicitly

$$
\begin{gathered}
\alpha\left(K^{s}+r w_{T-1}^{s}+w_{T}^{s}\right)^{\alpha-1}\left(r d w_{T-1}^{s}+d w_{T}^{s}\right)=\alpha\left(K^{s}+r w_{T-1}^{s}\right)^{\alpha-1} r d w_{T-1}^{s} \\
\frac{d w_{T}^{s}}{d w_{T-1}^{s}}=r \frac{\left(K^{s}+r w_{T-1}^{s}\right)^{\alpha-1}-\left(K^{s}+r w_{T-1}^{s}+w_{T}^{s}\right)^{\alpha-1}}{\left(K^{s}+r w_{T-1}^{s}+w_{T}^{s}\right)^{\alpha-1}}
\end{gathered}
$$

$\alpha<1$ so $\left(K^{s}+r w_{T-1}^{s}\right)^{\alpha-1}>\left(K^{s}+r w_{T-1}^{s}+w_{T}^{s}\right)^{\alpha-1}$ and the slope of locus (1) is always positive at any $w^{s}$. The same logic applies to locus (2):

$$
\begin{gathered}
\alpha\left(K^{s}+r w_{T-1}^{s}+w_{T}^{s}\right)^{\alpha-1}\left(r d w_{T-1}^{s}+d w_{T}^{s}\right)=\alpha\left(K^{s}+w_{T}^{s}\right)^{\alpha-1}\left(r d w_{T}^{s}\right) \\
\frac{d w_{T}^{s}}{d w_{T-1}^{s}}=r \frac{\left(K^{s}+r w_{T-1}^{s}\right)^{\alpha-1}-\left(K^{s}+r w_{T-1}^{s}+w_{T}^{s}\right)^{\alpha-1}}{\left(K^{s}+r w_{T-1}^{s}+w_{T}^{s}\right)^{\alpha-1}}
\end{gathered}
$$




\section{Comparative statics of the optimal lifecycle labour participation regimes}

In order to ascertain the effect of pension deferral on participation notice that with the exception of $r w_{T-1}^{s, 4}$, the critical wage expressions (as a function of $K^{s}$ ) all take the form:

$$
w^{s}=\left(\left(K^{s}+w^{s}\right)^{\alpha}+z\right)^{1 / \alpha}-K^{s}
$$

where $z>0$ is a combination of $\alpha, h_{T-1}, h_{T}$ and $D$. Note that in cases 7 and $8, \mathrm{z}$ does not depend on $s$. Differentiate wrt $K^{s}$

$$
\begin{aligned}
& \frac{d w^{s}}{d K}=\left(\left(K^{s}+w^{s}\right)^{\alpha}+z\right)^{(1-\alpha) / \alpha}\left(K^{s}+w^{s}\right)^{\alpha-1}-1 \\
& \quad=\left(1+z\left(K^{s}+w^{s}\right)^{-\alpha}\right)^{(1-\alpha) / \alpha}-1>0 \text { if } z>0
\end{aligned}
$$

In the case of (10) note that on the RHS of the expression we have $z=$ $\frac{\alpha}{D}\left(h_{T-1}-\delta h_{T}\right)$ so if $h_{T-1}>\delta h_{T}$ then $d w / d K>0$ but if $h_{T-1}<\delta h_{T}$ then $d w / d K<0$. So if $h_{T-1}>\delta h_{T}$ the wage region with full time work at $T$ expands at the expense of the wage region with full time work only in $T-1$.Or vice versa if $h_{T-1}<\delta h_{T}$. 